\title{
True and Apparent Scaling: The Proximity of the Markov-Switching Multifractal Model to Long-Range Dependence
}

\author{
Ruipeng Liu ${ }^{\mathrm{a}, \mathrm{b}}$, T. Di Matteo ${ }^{\mathrm{b}}$, Thomas Lux ${ }^{\mathrm{a}}$ \\ ${ }^{a}$ Department of Economics, University of Kiel, 24118 Kiel, Germany \\ ${ }^{\mathrm{b}}$ Department of Applied Mathematics, Research School of Physical Sciences and \\ Engineering, The Australian National University, 0200 Canberra, Australia
}

\begin{abstract}
In this paper, we consider daily financial data of a collection of different stock market indices, exchange rates, and interest rates, and we analyze their multi-scaling properties by estimating a simple specification of the Markov-switching multifractal model (MSM). In order to see how well the estimated models capture the temporal dependence of the data, we estimate and compare the scaling exponents $H(q)$ (for $q=1,2)$ for both empirical data and simulated data of the estimated MSM models. In most cases the multifractal model appears to generate 'apparent' long memory in agreement with the empirical scaling laws.
\end{abstract}

Key words: scaling, generalized Hurst exponent, multifractal model, GMM estimation

\section{Introduction}

The scaling concept has its origin in physics but it is increasingly applied outside its traditional domain. In the literature $([1,2,3])$ different methods have been proposed and developed in order to study the multi-scaling properties of financial time series. For more details on scaling analysis see [4].

Going beyond the phenomenological scaling analysis, the multifractal model of asset returns (MMAR) introduced by Mandelbrot et. al [5] provides a theoretical framework that allows to replicate many of the scaling properties of financial data. While the practical applicability of MMAR suffered from its combinatorial nature and its non-stationarity, these drawbacks have been overcome by the introduction of iterative multifractal models (Poisson MF or 
Markov-switching multifractal model (MSM) [6,7,8]) which preserves the hierarchical, multiplicative structure of the earlier MMAR, but is of much more 'well-behaved' nature concerning its asymptotic statistical properties. The attractiveness of MF models lies in their ability to mimic the stylized facts of financial markets such as outliers, volatility clustering, and asymptotic powerlaw behavior of autocovariance functions (long-term dependence). In contrast to other volatility models with long-term dependence [9], MSM models allow for multi-scaling rather than uni-scaling with varying decay exponents for all powers of absolute values of returns. One may note, however, that due to the Markovian nature, the scaling of the Markov-Switching MF model only holds over a limited range of time increments depending on the number of hierarchical components and this 'apparent' power-law ends with a cross-over to an exponential cut-off.

With this proximity to true multi-scaling, it seems worthwhile to explore how well the MSM model could reproduce the empirical scaling behaviour of financial data. To this end, we estimate the parameters of a simple specification of the MSM model for various financial data and we assess its ability to replicate empirical scaling behaviour by also computing $H(q)$ by means of the generalized Hurst exponent approach (4,10,11]) and $H$ by means of the modified $\mathrm{R} / \mathrm{S}$ method [12] for the same data sets. We then proceed by comparing the scaling exponents for empirical data and simulated time series based on our estimated MSM models. As it turns out, the MSM model with a sufficient number of volatility components generates pseudo-empirical scaling laws in good overall agreement with empirical results.

The structure of the paper is as follows: In Section 2 we introduce the multifractal model, the Generalized Hurst exponent (GHE) and the modified R/S approaches. Section 3 reports the empirical and simulation-based results. Concluding remarks and perspectives are given in Section 4.

\section{Methodology}

\subsection{Markov-switching multifractal model}

In this section, we shortly review the building blocks of the Markov-switching multifractal process (MSM). Returns are modeled as [7,8]:

$$
r_{t}=\sigma_{t} \cdot u_{t}
$$

with innovations $u_{t}$ drawn from a standard Normal distribution $N(0,1)$ and instantaneous volatility being determined by the product of $k$ volatility com- 
ponents or multipliers $M_{t}^{(1)}, M_{t}^{(2)} \ldots, M_{t}^{(k)}$ and a constant scale factor $\sigma$ :

$$
\sigma_{t}^{2}=\sigma^{2} \prod_{i=1}^{k} M_{t}^{(i)}
$$

In this paper we choose, for the distribution of volatility components, the binomial distribution: $M_{t}^{(i)} \sim\left[m_{0}, 2-m_{0}\right]$ with $1 \leq m_{0}<2$. Each volatility component is renewed at time $t$ with probability $\gamma_{i}$ depending on its rank within the hierarchy of multipliers and it remains unchanged with probability $1-\gamma_{i}$. The transition probabilities are specified by Calvet and Fisher [7] as:

$$
\gamma_{i}=1-\left(1-\gamma_{k}\right)^{\left(b^{i-k}\right)} \quad i=1, \ldots k
$$

with parameters $\gamma_{k} \in[0,1]$ and $b \in(1, \infty)$. Different specifications of Eq. (3) can be arbitrarily imposed (cf. [8] and its earlier versions). By fixing $b=2$ and $\gamma_{k}=0.5$, we arrive a relatively parsimonious specification:

$$
\gamma_{i}=1-\left(1-\gamma_{k}\right)^{\left(2^{i-k}\right)} \quad i=1, \ldots k .
$$

This specification implies that replacement happens with probability of one half at the highest cascade level. Various approaches have been employed to estimate multifractal models. The parameters of the combinatorial MMAR have been estimated via an adaptation of the scaling estimator and Legendre transformation approach from statistical physics [13. However, this approach has been shown to yield very unreliable results [14]. A broad range of more rigorous estimation methods have been developed for the MSM model. Calvet and Fisher (2001) ([6]) propose maximum likelihood estimation while Lux ([8]) proposes a Generalized Method of Moments (GMM) approach, which can be applied not only to discrete but also to continuous distributions of the volatility components. In this paper, GMM is used to estimate the two MSM model parameters in Eq. (2), namely: $\hat{\sigma}$ and $\hat{m}_{0}$.

\subsection{Estimation of scaling exponents}

Our analysis of the scaling behaviour of both empirical and simulated data uses two refined methods for estimating the time-honored Hurst coefficient: the estimation of generalized Hurst exponents from the structure function of various moments [4] and Lo's modified R/S analysis that allows to correct for short-range dependence in the temporal evolution of the range [12]. 


\subsubsection{Generalized Hurst exponent approach}

The generalized Hurst exponent (GHE) method extends the traditional scaling exponent methodology, and this approach provides a natural, unbiased, statistically and computationally efficient estimator able to capture very well the scaling features of financial fluctuations ([10,11]). It is essentially a tool to study directly the scaling properties of the data via the $q$ th order moments of the distribution of the increments. The $q$ th order moments appear to be less sensitive to the outliers than maxima/minima and different exponents $q$ are associated with different characterizations of the multi-scaling behaviour of the signal $X(t)$.

We consider the $q$-order moment of the distribution of the increments (with $t=v, 2 v, \ldots, T)$ of a time series $X(t)$ :

$$
K_{q}(\tau)=\frac{\left\langle|X(t+\tau)-X(t)|^{q}\right\rangle}{\left\langle|X(t)|^{q}\right\rangle},
$$

where the time interval $\tau$ varies between $v=1$ day and $\tau_{\max }$ days. The generalized Hurst exponent $H(q)$ is then defined from the scaling behavior of $K_{q}(\tau)$, which can be assumed to follow the relation:

$$
K_{q}(\tau) \sim\left(\frac{\tau}{v}\right)^{q H(q)} .
$$

Within this framework, for $q=1, H(1)$ describes the scaling behavior of the absolute values of the increments; for $q=2, H(2)$ is associated with the scaling of the autocorrelation function.

\subsubsection{Lo's modified $R / S$ analysis}

Lo's modified R/S analysis uses the range of a time series as its starting point: Formally, the range $R$ of a time series $\left\{X_{t}\right\}, t=1, \ldots, T$ is defined as:

$$
R_{T}=\max _{1 \leq t \leq T} \sum_{t=1}^{T}\left(X_{t}-\bar{X}\right)-\min _{1 \leq t \leq T} \sum_{t=1}^{T}\left(X_{t}-\bar{X}\right) .
$$

Here, $\bar{X}$ is the standard estimate of the mean. Usually the range is rescaled by the sample standard deviation $(S)$, yielding the famous R/S statistic. Though this approach found wide applications in diverse fields, it turned out that no asymptotic distribution theory could be derived for $\mathrm{H}$ itself. Hence, no explicit hypothesis testing can be performed and the significance of point estimates $H>0.5$ or $H<0.5$ rests on subjective assessment. Luckily, the asymptotic distribution of the rescaled range itself under a composite null hypothesis 
excluding long-memory could be established by Lo (1991) [12]. Using this distribution function and the critical values reported in his paper, one can test for the significance of apparent traces of long memory as indicated by $H \neq 0.5$. However, Lo also showed that the distributional properties of the rescaled range are affected by the presence of short memory and he devised a modified rescaled range $Q_{\tau}$ which adjusts for possible short memory effects by applying the Newey-West heteroscedasticity and autocorrelation consistent estimator in place of the sample standard deviation $S$ :

$$
\begin{aligned}
Q_{\tau} & =\frac{1}{S_{\tau}}\left[\max _{1 \leq t \leq T} \sum_{t=1}^{T}\left(X_{t}-\bar{X}\right)-\min _{1 \leq t \leq T} \sum_{t=1}^{T}\left(X_{t}-\bar{X}\right)\right], \\
S_{\tau}^{2} & =S^{2}+\frac{2}{T} \sum_{j=1}^{\tau} \omega_{j}(\tau)\left\{\sum_{i=j+1}^{T}\left(X_{i}-\bar{X}\right)\left(X_{i-j}-\bar{X}\right)\right\}, \\
\omega_{j}(\tau) & =1-\frac{j}{\tau+1} .
\end{aligned}
$$

Under the null of no long term memory the distribution of the random variable $V_{T}=T^{-0.5} Q_{\tau}$ converges to that of the range of a so-called Brownian bridge. Critical values of this distribution are tabulated in Lo (1991, Table II).

\section{Results}

In this paper, we consider daily data for a collection of stock exchange indices: the Dow Jones Composite 65 Average Index (Dow) and NIKKEI $225 \mathrm{Av}$ erage Index ( $N i k)$ over the time period from January 1969 to October 2004, foreign exchange rates: British Pound to US Dollar $(U K)$, and Australian Dollar to US Dollar $(A U)$ over the period from March 1973 to February 2004, and U.S. 1 year and 2 years treasury constant maturity bond rates (TB1 and $T B 2$, respectively) in the period from June 1976 to October 2004. The daily prices are denoted as $p_{t}$, and returns are calculated as $r_{t}=\ln \left(p_{t}\right)-\ln \left(p_{t-1}\right)$ for stock indices and foreign exchange rates and as $r_{t}=p_{t}-p_{t-1}$ for $T B 1$ and TB2.

We estimate the MSM model parameters introduced in Section 2 with a binomial distribution of volatility components, that is $M_{t}^{(\cdot)} \sim\left[m_{0}, 2-m_{0}\right]$ and $1 \leq m_{0}<2$ in Eq 2. This estimation is repeated for various hypothetical numbers of cascade levels $(k=5,10,15,20)$. Table 1 presents these results for parameters $\hat{m}_{0}$ and $\hat{\sigma} 1$ Our estimation is based on the GMM approach

$\overline{1}$ Note that the data have been standardized by dividing the sample standard deviation which explains the proximity of the scale parameter estimates to 1 . 
proposed by Lux [8] using the same analytical moments as in his paper. The numbers within the parentheses are the standard errors. We observe that the results for $k>10$ are almost identical. In fact, analytical moment conditions in Lux [8] show that higher cascade levels make a smaller and smaller contribution to the moments so that their numerical values would stay almost constant. If one monitors the development of estimated parameters with increasing $k$, one finds strong variations initially with a pronounced decrease of the estimates which become slower and slower until, eventually a constant value is reached somewhere around $k=10$ depending on individual time series. Based on the estimated parameters, we proceed with an analysis of simulated data from the pertinent MSM models.

We first calculate the GHE for the empirical time series as well as for 100 simulated time series of each set of estimated parameters for $q=1$ and $q=2$. The values of the GHE are averages computed from a set of values corresponding to different $\tau_{\max }$ (between 5 and 19 days). The stochastic variable $X(t)$ in Eq. (15) is the absolute value of returns, $X(t)=\left|r_{t}\right|$. The second and seventh columns in Table 2 report the empirical GHEs, and values in the other columns are the mean values over the corresponding 100 simulations for different $k$ values: $5,10,15,20$, with errors given by their standard deviations. Boldface numbers are those cases which fail to reject the null hypothesis that the mean of the simulation-based Generalized Hurst exponent values equals the empirical Generalized Hurst exponent at the 5\% level. We find that the exponents from the simulated time series vary across different cascade levels $k$. In particular, we observe considerable jumps from $k=5$ to $k=10$ for these values. In particular for the stock market indices, we find coincidence between the empirical series and simulation results for the scaling exponents $H(2)$ for Dow and $H(1)$ for $N i k$ when $k=5$. For the exchange rate data, we observe the simulations successfully replicate the empirical measurements of $A U$ for $H(1)$ when $k=10,15,20$ and $H(2)$ when $k=5$; In the case of U.S. Bond rates, we find a good agreement for $H(1)$ when $k=5$ and for all $k$ for $T B 1$, and $H(2)$ for $T B 2$ when $k=5$. Apparently, both the empirical data and the simulated MSM models are characterized by estimates of $H(1)$ and $H(2)$ much larger than 0.5 which are indicative of long-term dependence. While the empirical numbers are in nice agreement with previous literature, it is interesting to note that simulated data with $k \geq 10$ have a tendency towards even higher estimated Hurst coefficients than found in the pertinent empirical records 2 Since we know that the MSM model only has pre-asymptotic scaling, these results underscore that with a high enough number of volatility cascades, it would be hard to distinguish the MSM model from a 'true' long

2 We have checked if the generalized Hurst exponents approach is biased by computing $H(1)$ and $H(2)$ for random values generated by different random generators [11] with $T=9372$ data points. We have found that $H(1)=0.4999 \pm 0.009$ and $H(2)=0.4995 \pm 0.008$. 
memory process.

We have also performed calculations using the modified Rescaled range $(\mathrm{R} / \mathrm{S})$ analysis introduced by Lo [12,15,16,17, 18, 19,20, 3 whose results are reported in Tables 3 to 5 . Table 3 presents Lo's test statistics for both empirical and 1000 simulated time series for different values of $k$ and for different truncation lags $\tau=0,5,10,25,50,1004$ We find that the values are varying with different truncation lags, and more specifically, that they are monotonically decreasing for both the empirical and simulation-based statistics. Table 4 reports the number of rejections of the null hypothesis of short-range dependence based on $95 \%$ and $99 \%$ confidence levels. The rejection numbers for each single $k$ are decreasing as the truncation lag $\tau$ increases, but the proportion of rejections remains relatively high for higher cascade levels, $k=10,15,20$. The corresponding Hurst exponents are given in Table 5. The empirical values of $H$ are decreasing when $\tau$ increases. A similar behaviour is observed for the simulation-based $H$ for given values of $k$. We also observe that the Hurst exponent values are increasing with increasing cascade level $k$ for given $\tau$. Boldface numbers are those cases which fail to reject the null hypothesis that the mean of the simulation-based Hurst exponent equals the empirical Hurst exponent at the $5 \%$ level. There are significant jumps between the values for $k=5$ and $k=10$ as reported in previous tables.

Overall, the following results stand out: (1) There seems to be a good overall agreement between the empirical and simulated data for practically all series for levels $k \geq 10$, while with a smaller number of volatility components $(k=5)$ the simulated MSM models have typically smaller estimated $H$ s than the corresponding empirical data, (2) the modified R/S approach would quite reliably reject the null of long memory for $k=5$, but in most cases it would be unable to do so for higher numbers of volatility components, even if we allow for large truncation lags up to $\tau=100$. Results are also much more uniform than with the generalized Hurst technique which had left us with a rather mixed picture of coincidence of Hurst coefficients of empirical and simulated data. The fact, that according to Table 5, MSM model with 15 or more volatility components did always produce 'apparent' scaling in agreement with that of empirical data, is particular encouragingly. It contrasts with the findings reported in [19] on apparent scaling of estimated GARCH models whose estimated exponents did not agree with the empirical ones.

$\overline{3}$ We also did a Monte Carlo study with 1000 simulated random time series in order to assess the bias of the pertinent estimates of $H$ : for random numbers with sample size $T=9372$ (comparable to our empirical records) we obtained a slight negative bias: $H=0.463 \pm 0.024$.

4 For $\tau=0$ we have the classical $\mathrm{R} / \mathrm{S}$ approach. 


\section{Concluding Remarks}

We have calculated the scaling exponents of simulated data based on estimates of the Markov-switching multifractal (MSM) model. Comparing the generalized Hurst exponent values as well as Lo's Hurst exponent statistics of both empirical and simulated data, our study shows that the MSM model captures quite satisfactorily the multi-scaling properties of absolute values of returns for specifications with a sufficiently large number of volatility components. Subsequent work will explore whether this encouraging coincidence of the scaling statistics for the empirical and synthetic data also holds for other candidate distributions of volatility components and alternative specifications of the transition probabilities.

\section{Acknowledgments}

T. Di Matteo acknowledges the partial support by ARC Discovery Projects: DP03440044 (2003) and DP0558183 (2005), COST P10 "Physics of Risk" project and M.I.U.R.-F.I.S.R. Project "Ultra-high frequency dynamics of financial markets", T. Lux acknowledges financial support by the European Commission under STREP contract No. 516446.

\section{References}

[1] U. A. Müller, M. M. Dacorogna, R. B. Olsen, O. V. Pictet, M. Schwarz, C. Morgenegg, Journal of Banking and Finance 14, 1189-1208, (1990).

[2] M. M. Dacorogna, R. Gençay, U. A. Müller, R. B. Olsen, O. V. Pictet, An Introduction to High Frequency Finance Academic Press, San Diego, (2001).

[3] M. M. Dacorogna, U. A. Müller, R. B. Olsen, O. V. Pictet, Quantitative Finance 1, 198-201, (2001).

[4] T. Di Matteo, Quantitative Finance 7, 21-36, No. 1, (2007).

[5] B. Mandelbrot, A. Fisher, and L. Calvet, Cowles Foundation for Research and Economics Manuscript, (1997).

[6] L. Calvet, and A. Fisher, Journal of Econometrics 105, 27-58, (2001).

[7] L. Calvet, and A. Fisher, Journal of Financial Econometrics 84, 381-406, (2004).

[8] T. Lux, Journal of Business and Economic Statistics in Press, (2007).

[9] R. T. Baillie, T. Bollerslev, and H. Mikkelsen, Journal of Econometrics 74, 3-30, (1996). 
[10] T. Di Matteo, T. Aste, and M. Dacorogna, Physica A 324, 183-188, (2003).

[11] T. Di Matteo, T. Aste, and M. Dacorogna, Journal of Banking and Finance 29, 827-851, (2005).

[12] A. W. Lo, Econometrica 59, 1279-1313, (1991).

[13] L. Calvet, and A. Fisher, Review of Economics and Statistics 84, 381-406, (2002).

[14] T. Lux, International Journal of Modern Physics 15, 481-491, (2004).

[15] T. C. Mills, Applied Financial Economics, 3, 303-306, (1993).

[16] B. Huang and C. Yang, Applied Economic Letters, 2, 67-71, (1995).

[17] C. Brooks, Applied Economic Letters, 2, 428-431, (1995).

[18] T. Lux, Applied Economic Letters, 3, 701-706, (1996).

[19] N. Crato and P. J. F. de Lima, Economics Letters, 45, 281-285, (1996).

[20] Williger et al., Finance 8 Stochastics, 3, 1-13, (1999).

Table 1

GMM estimates of MSM model for different values of $\mathrm{k}$.

\begin{tabular}{|c|cc|cc|cc|cc|}
\hline & \multicolumn{2}{|c|}{$\mathrm{k}=5$} & \multicolumn{2}{c|}{$\mathrm{k}=10$} & \multicolumn{2}{c|}{$\mathrm{k}=15$} & \multicolumn{2}{c|}{$\mathrm{k}=20$} \\
\hline \multirow{2}{*}{ Dow } & $\hat{m}_{0}$ & $\hat{\sigma}$ & $\hat{m}_{0}$ & $\hat{\sigma}$ & $\hat{m}_{0}$ & $\hat{\sigma}$ & $\hat{m}_{0}$ & $\hat{\sigma}$ \\
& 1.498 & 0.983 & 1.484 & 0.983 & 1.485 & 0.983 & 1.487 & 0.983 \\
Nik & 1.641 & 0.991 & 1.634 & 0.991 & 1.635 & 0.991 & 1.636 & 0.991 \\
& $(0.017)$ & $(0.036)$ & $(0.013)$ & $(0.028)$ & $(0.017)$ & $(0.036)$ & $(0.017)$ & $(0.037)$ \\
UK & 1.415 & 1.053 & 1.382 & 1.057 & 1.381 & 1.056 & 1.381 & 1.058 \\
& $(0.033)$ & $(0.026)$ & $(0.029)$ & $(0.027)$ & $(0.036)$ & $(0.027)$ & $(0.038)$ & $(0.026)$ \\
AU & 1.487 & 1.011 & 1.458 & 1.013 & 1.457 & 1.014 & 1.458 & 1.014 \\
& $(0.034)$ & $(0.066)$ & $(0.034)$ & $(0.061)$ & $(0.034)$ & $(0.066)$ & $(0.034)$ & $(0.065)$ \\
$T B 1$ & 1.627 & 1.041 & 1.607 & 1.064 & 1.607 & 1.064 & 1.606 & 1.067 \\
& $(0.021)$ & $(0.032)$ & $(0.025)$ & $(0.024)$ & $(0.028)$ & $(0.024)$ & $(0.025)$ & $(0.024)$ \\
$T B 2$ & 1.703 & 1.040 & 1.679 & 1.068 & 1.678 & 1.079 & 1.678 & 1.079 \\
& $(0.015)$ & $(0.036)$ & $(0.014)$ & $(0.029)$ & $(0.015)$ & $(0.032)$ & $(0.015)$ & $(0.034)$ \\
\hline
\end{tabular}

Note: All data have been standardized before estimation. 
Table 2

$\mathrm{H}(1)$ and $\mathrm{H}(2)$ for the empirical and simulated data.

\begin{tabular}{|c|c|c|c|c|c|c|c|c|c|c|}
\hline & \multicolumn{5}{|c|}{$H(1)$} & \multicolumn{5}{|c|}{$H(2)$} \\
\hline & $E m p$ & $\operatorname{sim} 1$ & $\operatorname{sim} 2$ & $\operatorname{sim} 3$ & $\operatorname{sim} 4$ & $E m p$ & $\operatorname{sim} 1$ & $\operatorname{sim} 2$ & $\operatorname{sim} 3$ & $\operatorname{sim} 4$ \\
\hline \multirow[t]{2}{*}{ Dow } & 0.684 & 0.747 & 0.849 & 0.868 & 0.868 & 0.709 & 0.705 & 0.797 & 0.813 & 0.812 \\
\hline & $(0.034)$ & $(0.008)$ & $(0.015)$ & $(0.021)$ & $(0.024)$ & $(0.027)$ & $(0.009)$ & $(0.015)$ & $(0.019)$ & $(0.022)$ \\
\hline \multirow[t]{2}{*}{$N i k$} & 0.788 & 0.801 & 0.894 & 0.908 & 0.908 & 0.753 & 0.736 & 0.815 & 0.824 & 0.824 \\
\hline & $(0.023)$ & $(0.008)$ & $(0.013)$ & $(0.019)$ & $(0.028)$ & $(0.021)$ & $(0.008)$ & $(0.013)$ & $(0.018)$ & $(0.024)$ \\
\hline \multirow[t]{2}{*}{$U K$} & 0.749 & 0.709 & 0.799 & 0.825 & 0.821 & 0.735 & 0.678 & 0.764 & 0.785 & 0.783 \\
\hline & $(0.023)$ & $(0.010)$ & $(0.018)$ & $(0.025)$ & $(0.026)$ & $(0.026)$ & $(0.010)$ & $(0.016)$ & $(0.021)$ & $(0.022)$ \\
\hline \multirow[t]{2}{*}{$A U$} & 0.827 & 0.746 & 0.837 & 0.860 & 0.857 & 0.722 & 0.705 & 0.790 & 0.808 & 0.808 \\
\hline & $(0.017)$ & $(0.009)$ & $(0.016)$ & $(0.022)$ & $(0.021)$ & $(0.024)$ & $(0.009)$ & $(0.015)$ & $(0.018)$ & $(0.018)$ \\
\hline \multirow[t]{2}{*}{$T B 1$} & 0.853 & 0.856 & 0.909 & 0.915 & 0.911 & 0.814 & 0.783 & 0.826 & 0.832 & 0.829 \\
\hline & $(0.022)$ & $(0.035)$ & $(0.023)$ & $(0.026)$ & $(0.026)$ & $(0.027)$ & $(0.028)$ & $(0.020)$ & $(0.020)$ & $(0.020)$ \\
\hline \multirow[t]{2}{*}{$T B 2$} & 0.791 & 0.866 & 0.920 & 0.924 & 0.919 & 0.778 & 0.781 & 0.823 & 0.827 & 0.822 \\
\hline & $(0.025)$ & $(0.029)$ & $(0.021)$ & $(0.022)$ & $(0.026)$ & $(0.029)$ & $(0.022)$ & $(0.017)$ & $(0.022)$ & $(0.023)$ \\
\hline
\end{tabular}

Note: Emp refers to the empirical exponent values, $\operatorname{sim} 1, \operatorname{sim} 2, \operatorname{sim} 3$ and $\operatorname{sim} 4$ are the corresponding exponent values based on the simulated data for $k=5, k=10$, $k=15$ and $k=20$ respectively. The stochastic variable $X_{t}$ is defined as $\left|r_{t}\right|$. Bold numbers show those cases for which we cannot reject identity of the Hurst coefficients obtained for empirical and simulated data, i.e. the empirical exponents fall into the range between the 2.5 to 97.5 percent quantile of the simulated data. 
Table 3

Lo's R/S statistic for the empirical and simulated data.

\begin{tabular}{|c|c|c|c|c|c|c|c|c|c|c|c|c|c|c|c|}
\hline & \multicolumn{5}{|c|}{$\tau=0$} & \multicolumn{5}{|c|}{$\tau=5$} & \multicolumn{5}{|c|}{$\tau=10$} \\
\hline & $E m p$ & $k=5$ & $k=10$ & $k=15$ & $k=20$ & $E m p$ & $k=5$ & $k=10$ & $k=15$ & $k=20$ & $E m p$ & $k=5$ & $k=10$ & $k=15$ & $k=20$ \\
\hline Dow & 3.005 & $\begin{array}{c}1.712 \\
(0.381)\end{array}$ & $\begin{array}{c}5.079 \\
(1.300)\end{array}$ & $\begin{array}{c}6.640 \\
(1.769)\end{array}$ & $\begin{array}{c}6.704 \\
(1.839)\end{array}$ & 2.661 & $\begin{array}{c}1.481 \\
(0.329)\end{array}$ & $\begin{array}{c}4.060 \\
(1.017)\end{array}$ & $\begin{array}{c}5.211 \\
(1.333)\end{array}$ & $\begin{array}{c}5.263 \\
(1.387)\end{array}$ & 2.427 & $\begin{array}{c}1.376 \\
(0.305)\end{array}$ & $\begin{array}{c}3.574 \\
(0.884)\end{array}$ & $\begin{array}{c}4.537 \\
(1.133)\end{array}$ & $\begin{array}{c}4.582 \\
(1.179)\end{array}$ \\
\hline$N i k$ & 7.698 & $\begin{array}{c}1.840 \\
(0.425)\end{array}$ & $\begin{array}{c}4.898 \\
(1.195)\end{array}$ & $\begin{array}{c}6.154 \\
(1.520)\end{array}$ & $\begin{array}{c}6.152 \\
(1.584)\end{array}$ & 6.509 & $\begin{array}{c}1.540 \\
(0.355)\end{array}$ & $\begin{array}{c}3.817 \\
(0.918)\end{array}$ & $\begin{array}{c}4.747 \\
(1.147)\end{array}$ & $\begin{array}{c}4.742 \\
(1.193)\end{array}$ & 5.836 & $\begin{array}{c}1.416 \\
(0.325)\end{array}$ & $\begin{array}{c}3.343 \\
(0.798)\end{array}$ & $\begin{array}{c}4.132 \\
(0.984)\end{array}$ & $\begin{array}{c}4.133 \\
(1.023)\end{array}$ \\
\hline$U K$ & 6.821 & $\begin{array}{c}1.544 \\
(0.350)\end{array}$ & $\begin{array}{c}4.599 \\
(1.200)\end{array}$ & $\begin{array}{c}6.047 \\
(1.748)\end{array}$ & $\begin{array}{c}6.175 \\
(1.848)\end{array}$ & 5.912 & $\begin{array}{c}1.370 \\
(0.310)\end{array}$ & $\begin{array}{c}3.815 \\
(0.972)\end{array}$ & $\begin{array}{c}4.918 \\
(1.352)\end{array}$ & $\begin{array}{c}5.008 \\
(1.417)\end{array}$ & 5.333 & $\begin{array}{c}1.286 \\
(0.290)\end{array}$ & $\begin{array}{c}3.405 \\
(0.854)\end{array}$ & $\begin{array}{c}4.337 \\
(1.157)\end{array}$ & $\begin{array}{c}4.408 \\
(1.207)\end{array}$ \\
\hline$A U$ & 7.698 & $\begin{array}{c}1.687 \\
(0.386)\end{array}$ & $\begin{array}{c}4.962 \\
(1.257)\end{array}$ & $\begin{array}{c}6.348 \\
(1.742)\end{array}$ & $\begin{array}{c}6.434 \\
(1.790)\end{array}$ & 6.731 & $\begin{array}{c}1.463 \\
(0.333)\end{array}$ & $\begin{array}{c}4.001 \\
(0.989)\end{array}$ & $\begin{array}{c}5.024 \\
(1.315)\end{array}$ & $\begin{array}{c}5.090 \\
(1.352)\end{array}$ & 6.103 & $\begin{array}{c}1.361 \\
(0.309)\end{array}$ & $\begin{array}{c}3.531 \\
(0.861)\end{array}$ & $\begin{array}{c}4.387 \\
(1.117)\end{array}$ & $\begin{array}{c}4.443 \\
(1.149)\end{array}$ \\
\hline$T B 1$ & 8.845 & $\begin{array}{c}1.826 \\
(0.398)\end{array}$ & $\begin{array}{c}4.644 \\
(1.141)\end{array}$ & $\begin{array}{c}5.915 \\
(1.425)\end{array}$ & $\begin{array}{c}6.041 \\
(1.380)\end{array}$ & 7.109 & $\begin{array}{c}1.524 \\
(0.330)\end{array}$ & $\begin{array}{c}3.629 \\
(0.875)\end{array}$ & $\begin{array}{c}4.564 \\
(1.074)\end{array}$ & $\begin{array}{c}4.582 \\
(1.040)\end{array}$ & 6.110 & $\begin{array}{c}1.400 \\
(0.302)\end{array}$ & $\begin{array}{c}3.184 \\
(0.759)\end{array}$ & $\begin{array}{c}4.415 \\
(0.921)\end{array}$ & $\begin{array}{c}4.530 \\
(0.891)\end{array}$ \\
\hline$T B 2$ & 7.295 & $\begin{array}{c}1.855 \\
(0.413)\end{array}$ & $\begin{array}{c}4.347 \\
(1.031)\end{array}$ & $\begin{array}{c}5.853 \\
(1.215)\end{array}$ & $\begin{array}{c}5.907 \\
(1.227)\end{array}$ & 6.083 & $\begin{array}{c}1.531 \\
(0.339)\end{array}$ & $\begin{array}{c}3.391 \\
(0.795)\end{array}$ & $\begin{array}{c}4.207 \\
(0.928)\end{array}$ & $\begin{array}{c}4.349 \\
(0.930)\end{array}$ & 5.330 & $\begin{array}{c}1.404 \\
(0.310)\end{array}$ & $\begin{array}{c}2.985 \\
(0.694)\end{array}$ & $\begin{array}{c}4.025 \\
(0.804)\end{array}$ & $\begin{array}{c}4.158 \\
(0.803)\end{array}$ \\
\hline & \multicolumn{5}{|c|}{$\tau=25$} & \multicolumn{5}{|c|}{$\tau=50$} & \multicolumn{5}{|c|}{$\tau=100$} \\
\hline & $E m p$ & $k=5$ & $k=10$ & $k=15$ & $k=20$ & $E m p$ & $k=5$ & $k=10$ & $k=15$ & $k=20$ & $E m p$ & $k=5$ & $k=10$ & $k=15$ & $k=20$ \\
\hline Dow & 2.042 & $\begin{array}{c}1.237 \\
(0.272)\end{array}$ & $\begin{array}{c}2.877 \\
(0.694)\end{array}$ & $\begin{array}{c}3.580 \\
(0.857)\end{array}$ & $\begin{array}{c}3.616 \\
(0.893)\end{array}$ & 1.736 & $\begin{array}{c}1.153 \\
(0.250)\end{array}$ & $\begin{array}{c}2.385 \\
(0.560)\end{array}$ & $\begin{array}{c}2.909 \\
(0.668)\end{array}$ & $\begin{array}{c}2.941 \\
(0.696)\end{array}$ & 1.464 & $\begin{array}{c}1.098 \\
(0.233)\end{array}$ & $\begin{array}{c}1.965 \\
(0.443)\end{array}$ & $\begin{array}{c}2.338 \\
(0.508)\end{array}$ & $\begin{array}{c}2.366 \\
(0.530)\end{array}$ \\
\hline$N i k$ & 4.760 & $\begin{array}{c}1.260 \\
(0.286)\end{array}$ & $\begin{array}{c}2.692 \\
(0.631)\end{array}$ & $\begin{array}{c}3.285 \\
(0.761)\end{array}$ & $\begin{array}{c}3.279 \\
(0.788)\end{array}$ & 3.941 & $\begin{array}{c}1.169 \\
(0.263)\end{array}$ & $\begin{array}{c}2.246 \\
(0.514)\end{array}$ & $\begin{array}{c}2.701 \\
(0.604)\end{array}$ & $\begin{array}{c}2.698 \\
(0.623)\end{array}$ & 3.220 & $\begin{array}{c}1.113 \\
(0.245)\end{array}$ & $\begin{array}{c}1.868 \\
(0.412)\end{array}$ & $\begin{array}{c}2.204 \\
(0.468)\end{array}$ & $\begin{array}{c}2.203 \\
(0.482)\end{array}$ \\
\hline$U K$ & 4.348 & $\begin{array}{c}1.170 \\
(0.262)\end{array}$ & $\begin{array}{c}2.782 \\
(0.678)\end{array}$ & $\begin{array}{c}3.469 \\
(0.876)\end{array}$ & $\begin{array}{c}3.515 \\
(0.909)\end{array}$ & 3.575 & $\begin{array}{c}1.099 \\
(0.244)\end{array}$ & $\begin{array}{c}2.322 \\
(0.549)\end{array}$ & $\begin{array}{c}2.837 \\
(0.680)\end{array}$ & $\begin{array}{c}2.868 \\
(0.702)\end{array}$ & 2.871 & $\begin{array}{c}1.053 \\
(0.228)\end{array}$ & $\begin{array}{c}1.922 \\
(0.434)\end{array}$ & $\begin{array}{c}2.289 \\
(0.513)\end{array}$ & $\begin{array}{c}2.306 \\
(0.528)\end{array}$ \\
\hline$A U$ & 5.035 & $\begin{array}{c}1.224 \\
(0.275)\end{array}$ & $\begin{array}{c}2.848 \\
(0.676)\end{array}$ & $\begin{array}{c}3.474 \\
(0.842)\end{array}$ & $\begin{array}{c}3.516 \\
(0.866)\end{array}$ & 4.130 & $\begin{array}{c}1.142 \\
(0.252)\end{array}$ & $\begin{array}{c}2.362 \\
(0.544)\end{array}$ & $\begin{array}{c}2.830 \\
(0.654)\end{array}$ & $\begin{array}{c}2.861 \\
(0.672)\end{array}$ & 3.281 & $\begin{array}{c}1.089 \\
(0.232)\end{array}$ & $\begin{array}{c}1.947 \\
(0.429)\end{array}$ & $\begin{array}{c}2.280 \\
(0.496)\end{array}$ & $\begin{array}{c}2.302 \\
(0.508)\end{array}$ \\
\hline$T B 1$ & 4.580 & $\begin{array}{c}1.245 \\
(0.265)\end{array}$ & $\begin{array}{c}2.571 \\
(0.598)\end{array}$ & $\begin{array}{c}2.961 \\
(0.711)\end{array}$ & $\begin{array}{c}2.971 \\
(0.685)\end{array}$ & 3.514 & $\begin{array}{c}1.156 \\
(0.242)\end{array}$ & $\begin{array}{c}2.148 \\
(0.484)\end{array}$ & $\begin{array}{c}2.442 \\
(0.564)\end{array}$ & $\begin{array}{c}2.449 \\
(0.542)\end{array}$ & 2.649 & $\begin{array}{c}1.101 \\
(0.223)\end{array}$ & $\begin{array}{c}1.790 \\
(0.384)\end{array}$ & $\begin{array}{c}2.004 \\
(0.440)\end{array}$ & $\begin{array}{c}2.006 \\
(0.417)\end{array}$ \\
\hline$T B 2$ & 4.129 & $\begin{array}{c}1.249 \\
(0.272)\end{array}$ & $\begin{array}{c}2.432 \\
(0.554)\end{array}$ & $\begin{array}{c}2.762 \\
(0.632)\end{array}$ & $\begin{array}{c}2.786 \\
(0.630)\end{array}$ & 3.250 & $\begin{array}{c}1.162 \\
(0.249)\end{array}$ & $\begin{array}{c}2.052 \\
(0.456)\end{array}$ & $\begin{array}{c}2.305 \\
(0.511)\end{array}$ & $\begin{array}{c}2.320 \\
(0.507)\end{array}$ & 2.502 & $\begin{array}{c}1.109 \\
(0.230)\end{array}$ & $\begin{array}{c}1.731 \\
(0.369)\end{array}$ & $\begin{array}{c}1.915 \\
(0.403)\end{array}$ & $\begin{array}{c}1.921 \\
(0.398)\end{array}$ \\
\hline
\end{tabular}

Note: Emp stands for the empirical Lo's statistic, $k=5, k=10, k=15$ and $k=20$ refer to the mean and standard deviation of Lo's statistics based

on the corresponding 1000 simulated time series with pertinent $k$ 
Table 4

Number of rejections for Lo's R/S statistic test.

\begin{tabular}{|c|c|c|c|c|c|c|c|c|c|c|c|c|c|c|c|c|c|c|c|c|c|c|c|c|}
\hline & \multicolumn{8}{|c|}{$\tau=0$} & \multicolumn{8}{|c|}{$\tau=5$} & \multicolumn{8}{|c|}{$\tau=10$} \\
\hline & \multicolumn{2}{|c|}{$k=5$} & \multicolumn{2}{|c|}{$k=10$} & \multicolumn{2}{|c|}{$k=15$} & \multicolumn{2}{|c|}{$k=20$} & \multicolumn{2}{|c|}{$k=5$} & \multicolumn{2}{|c|}{$k=10$} & \multicolumn{2}{|c|}{$k=15$} & \multicolumn{2}{|c|}{$k=20$} & \multicolumn{2}{|c|}{$k=5$} & \multicolumn{2}{|c|}{$k=10$} & \multicolumn{2}{|c|}{$k=15$} & \multicolumn{2}{|c|}{$k=20$} \\
\hline & $\dagger$ & $\ddagger$ & $\dagger$ & $\ddagger$ & $\dagger$ & $\ddagger$ & $\dagger$ & $\ddagger$ & $\dagger$ & $\ddagger$ & $\dagger$ & $\ddagger$ & $\dagger$ & $\ddagger$ & $\dagger$ & $\ddagger$ & $\dagger$ & $\ddagger$ & $\dagger$ & $\ddagger$ & $\dagger$ & $\ddagger$ & $\dagger$ & $\ddagger$ \\
\hline Dow & 311 & 151 & 1000 & 1000 & 1000 & 1000 & 1000 & 1000 & 121 & 46 & 999 & 991 & 999 & 998 & 1000 & 1000 & 69 & 22 & 990 & 968 & 998 & 997 & 1000 & 995 \\
\hline$N i k$ & 433 & 253 & 1000 & 999 & 1000 & 1000 & 1000 & 1000 & 176 & 74 & 993 & 985 & 998 & 997 & 1000 & 999 & 98 & 36 & 983 & 963 & 997 & 991 & 999 & 993 \\
\hline$U K$ & 167 & 77 & 998 & 995 & 1000 & 999 & 999 & 998 & 74 & 22 & 991 & 976 & 998 & 997 & 998 & 997 & 41 & 7 & 982 & 943 & 996 & 990 & 997 & 992 \\
\hline$A U$ & 301 & 142 & 1000 & 999 & 999 & 999 & 1000 & 1000 & 116 & 39 & 997 & 990 & 998 & 994 & 1000 & 999 & 58 & 23 & 990 & 966 & 993 & 989 & 999 & 995 \\
\hline$T B 1$ & 428 & 227 & 1000 & 1000 & 1000 & 999 & 999 & 999 & 146 & 55 & 993 & 976 & 997 & 991 & 998 & 996 & 75 & 24 & 976 & 934 & 990 & 970 & 996 & 989 \\
\hline \multirow[t]{4}{*}{$T B 2$} & 453 & 256 & 999 & 995 & 998 & 997 & 1000 & 999 & 159 & 60 & 987 & 959 & 994 & 982 & 996 & 986 & 86 & 21 & 958 & 899 & 985 & 961 & 985 & 960 \\
\hline & \multicolumn{8}{|c|}{$\tau=25$} & \multicolumn{8}{|c|}{$\tau=50$} & \multicolumn{8}{|c|}{$\tau=100$} \\
\hline & \multicolumn{2}{|c|}{$k=5$} & \multicolumn{2}{|c|}{$k=10$} & \multicolumn{2}{|c|}{$k=15$} & \multicolumn{2}{|c|}{$k=20$} & \multicolumn{2}{|c|}{$k=5$} & \multicolumn{2}{|c|}{$k=10$} & \multicolumn{2}{|c|}{$k=15$} & \multicolumn{2}{|c|}{$k=20$} & \multicolumn{2}{|c|}{$k=5$} & & & $k=$ & & & \\
\hline & $\dagger$ & $\ddagger$ & $\dagger$ & $\ddagger$ & $\dagger$ & $\ddagger$ & $\dagger$ & $\ddagger$ & $\dagger$ & $\ddagger$ & $\dagger$ & $\ddagger$ & $\dagger$ & $\ddagger$ & $\dagger$ & $\ddagger$ & $\dagger$ & $\ddagger$ & $\dagger$ & $\ddagger$ & $\dagger$ & $\ddagger$ & $\dagger$ & $\ddagger$ \\
\hline Dow & 24 & 5 & 939 & 858 & 990 & 964 & 985 & 966 & 9 & 3 & 807 & 677 & 940 & 887 & 948 & 872 & 4 & 1 & 566 & 381 & 811 & 669 & 808 & 686 \\
\hline$N i k$ & 34 & 5 & 920 & 809 & 982 & 848 & 977 & 930 & 11 & 2 & 764 & 581 & 914 & 831 & 897 & 812 & 4 & 1 & 485 & 281 & 750 & 582 & 742 & 575 \\
\hline$U K$ & 11 & 1 & 929 & 843 & 982 & 942 & 979 & 953 & 4 & 1 & 789 & 630 & 919 & 840 & 926 & 843 & 1 & 1 & 541 & 327 & 783 & 632 & 774 & 640 \\
\hline$A U$ & 23 & 5 & 931 & 860 & 983 & 949 & 983 & 956 & 6 & 2 & 816 & 666 & 921 & 852 & 931 & 846 & 4 & 1 & 561 & 353 & 776 & 648 & 786 & 649 \\
\hline$T B 1$ & 25 & 4 & 876 & 765 & 946 & 870 & 965 & 893 & 5 & 1 & 698 & 519 & 822 & 711 & 846 & 712 & 1 & 1 & 418 & 230 & 627 & 415 & 604 & 400 \\
\hline$T B 2$ & 21 & 6 & 844 & 696 & 933 & 851 & 928 & 859 & 10 & 3 & 627 & 446 & 798 & 638 & 807 & 657 & 3 & 1 & 368 & 167 & 534 & 312 & 544 & 336 \\
\hline
\end{tabular}

Note: $k=5, k=10, k=15$ and $k=20$ refer to the number of rejections at $95 \%(\dagger)$ and $99 \%$ ( $\ddagger$ ) confidence levels (these intervals are given by [0.809, 1.862] and [0.721, 2.098], respectively) for the 1000 simulated time series. 
Table 5

Lo's modified R/S Hurst exponent $H$ values for the empirical and simulated data.

\begin{tabular}{|c|c|c|c|c|c|c|c|c|c|c|c|c|c|c|c|}
\hline & \multicolumn{5}{|c|}{$\tau=0$} & \multicolumn{5}{|c|}{$\tau=5$} & \multicolumn{5}{|c|}{$\tau=10$} \\
\hline & $E m p$ & $k=5$ & $k=10$ & $k=15$ & $k=20$ & $E m p$ & $k=5$ & $k=10$ & $k=15$ & $k=20$ & $E m p$ & $k=5$ & $k=10$ & $k=15$ & $k=20$ \\
\hline Dow & 0.620 & $\begin{array}{c}0.556 \\
(0.024)\end{array}$ & $\begin{array}{r}\mathbf{0 . 6 7 4} \\
(0.029)\end{array}$ & $\begin{array}{c}\mathbf{0 . 7 0 3} \\
(0.030)\end{array}$ & $\begin{array}{c}\mathbf{0 . 7 0 4} \\
(0.031)\end{array}$ & 0.607 & $\begin{array}{c}0.540 \\
(0.024)\end{array}$ & $\begin{array}{c}\mathbf{0 . 6 5 0} \\
(0.028)\end{array}$ & $\begin{array}{r}\mathbf{0 . 6 7 7} \\
(0.029)\end{array}$ & $\begin{array}{r}\mathbf{0 . 6 7 8} \\
(0.030)\end{array}$ & 0.597 & $\begin{array}{c}0.532 \\
(0.024)\end{array}$ & $\begin{array}{c}\mathbf{0 . 6 3 6} \\
(0.028)\end{array}$ & $\begin{array}{c}\mathbf{0 . 6 6 2} \\
(0.028)\end{array}$ & $\begin{array}{r}\mathbf{0 . 6 6 3} \\
(0.029)\end{array}$ \\
\hline$N i k$ & 0.723 & $\begin{array}{c}0.564 \\
(0.025)\end{array}$ & $\begin{array}{c}0.670 \\
(0.027)\end{array}$ & $\begin{array}{c}\mathbf{0 . 6 9 5} \\
(0.028)\end{array}$ & $\begin{array}{r}\mathbf{0 . 6 9 5} \\
(0.029)\end{array}$ & 0.705 & $\begin{array}{c}0.544 \\
(0.025)\end{array}$ & $\begin{array}{c}0.643 \\
(0.027)\end{array}$ & $\begin{array}{c}\mathbf{0 . 6 6 7} \\
(0.028)\end{array}$ & $\begin{array}{c}\mathbf{0 . 6 6 7} \\
(0.029)\end{array}$ & 0.693 & $\begin{array}{c}0.535 \\
(0.025)\end{array}$ & $\begin{array}{c}0.629 \\
(0.027)\end{array}$ & $\begin{array}{r}\mathbf{0 . 6 5 2} \\
(0.027)\end{array}$ & $\begin{array}{c}\mathbf{0 . 6 5 1} \\
(0.028)\end{array}$ \\
\hline$U K$ & 0.712 & $\begin{array}{c}0.545 \\
(0.025)\end{array}$ & $\begin{array}{c}\mathbf{0 . 6 6 5} \\
(0.030)\end{array}$ & $\begin{array}{l}\mathbf{0 . 6 9 4} \\
(0.033)\end{array}$ & $\begin{array}{l}\mathbf{0 . 6 9 6} \\
(0.036)\end{array}$ & 0.696 & $\begin{array}{c}0.532 \\
(0.025)\end{array}$ & $\begin{array}{c}0.644 \\
(0.029)\end{array}$ & $\begin{array}{r}\mathbf{0 . 6 7 2} \\
(0.032)\end{array}$ & $\begin{array}{r}\mathbf{0 . 6 7 3} \\
(0.035)\end{array}$ & 0.685 & $\begin{array}{c}0.525 \\
(0.025)\end{array}$ & $\begin{array}{c}0.632 \\
(0.029)\end{array}$ & $\begin{array}{c}\mathbf{0 . 6 5 8} \\
(0.031)\end{array}$ & $\begin{array}{r}\mathbf{0 . 6 6 0} \\
(0.034)\end{array}$ \\
\hline$A U$ & 0.726 & $\begin{array}{c}0.555 \\
(0.025)\end{array}$ & $\begin{array}{c}0.673 \\
(0.029)\end{array}$ & $\begin{array}{c}\mathbf{0 . 7 0 0} \\
(0.032)\end{array}$ & $\begin{array}{c}\mathbf{0 . 7 0 1} \\
(0.032)\end{array}$ & 0.711 & $\begin{array}{c}0.539 \\
(0.025)\end{array}$ & $\begin{array}{c}0.650 \\
(0.028)\end{array}$ & $\begin{array}{c}\mathbf{0 . 6 7 4} \\
(0.031)\end{array}$ & $\begin{array}{r}\mathbf{0 . 6 7 6} \\
(0.031)\end{array}$ & 0.700 & $\begin{array}{c}0.531 \\
(0.025)\end{array}$ & $\begin{array}{c}0.636 \\
(0.028)\end{array}$ & $\begin{array}{r}\mathbf{0 . 6 6 0} \\
(0.030)\end{array}$ & $\begin{array}{c}\mathbf{0 . 6 6 1} \\
(0.030)\end{array}$ \\
\hline$T B 1$ & 0.746 & $\begin{array}{c}0.565 \\
(0.024)\end{array}$ & $\begin{array}{c}0.670 \\
(0.028)\end{array}$ & $\begin{array}{c}\mathbf{0 . 6 8 9} \\
(0.031)\end{array}$ & $\begin{array}{c}\mathbf{0 . 6 9 1} \\
(0.029)\end{array}$ & 0.721 & $\begin{array}{c}0.547 \\
(0.024)\end{array}$ & $\begin{array}{c}0.642 \\
(0.028)\end{array}$ & $\begin{array}{r}\mathbf{0 . 6 6 0} \\
(0.030)\end{array}$ & $\begin{array}{c}\mathbf{0 . 6 6 1} \\
(0.028)\end{array}$ & 0.704 & $\begin{array}{c}0.535 \\
(0.024)\end{array}$ & $\begin{array}{c}0.627 \\
(0.028)\end{array}$ & $\begin{array}{c}\mathbf{0 . 6 4 4} \\
(0.029)\end{array}$ & $\begin{array}{r}\mathbf{0 . 6 4 5} \\
(0.028)\end{array}$ \\
\hline$T B 2$ & 0.724 & $\begin{array}{c}0.567 \\
(0.025)\end{array}$ & $\begin{array}{c}0.662 \\
(0.028)\end{array}$ & $\begin{array}{c}\mathbf{0 . 6 7 9} \\
(0.028)\end{array}$ & $\begin{array}{r}\mathbf{0 . 6 8 0} \\
(0.028)\end{array}$ & 0.704 & $\begin{array}{c}0.545 \\
(0.025)\end{array}$ & $\begin{array}{c}0.634 \\
(0.027)\end{array}$ & $\begin{array}{r}\mathbf{0 . 6 5 0} \\
(0.028)\end{array}$ & $\begin{array}{r}\mathbf{0 . 6 5 2} \\
(0.028) \\
\end{array}$ & 0.689 & $\begin{array}{c}0.536 \\
(0.024)\end{array}$ & $\begin{array}{c}0.620 \\
(0.027)\end{array}$ & $\begin{array}{r}\mathbf{0 . 6 3 6} \\
(0.028)\end{array}$ & $\begin{array}{r}\mathbf{0 . 6 3 7} \\
(0.027)\end{array}$ \\
\hline & \multicolumn{5}{|c|}{$\tau=25$} & \multicolumn{5}{|c|}{$\tau=50$} & \multicolumn{5}{|c|}{$\tau=100$} \\
\hline & $E m p$ & $k=5$ & $k=10$ & $k=15$ & $k=20$ & $E m p$ & $k=5$ & $k=10$ & $k=15$ & $k=20$ & $E m p$ & $k=5$ & $k=10$ & $k=15$ & $k=20$ \\
\hline Dow & 0.578 & $\begin{array}{c}0.521 \\
(0.024)\end{array}$ & $\begin{array}{c}\mathbf{0 . 6 1 2} \\
(0.027)\end{array}$ & $\begin{array}{c}\mathbf{0 . 6 3 6} \\
(0.027)\end{array}$ & $\begin{array}{c}\mathbf{0 . 6 3 7} \\
(0.028)\end{array}$ & 0.560 & $\begin{array}{c}0.513 \\
(0.023)\end{array}$ & $\begin{array}{c}\mathbf{0 . 5 9 2} \\
(0.026)\end{array}$ & $\begin{array}{r}\mathbf{0 . 6 1 4} \\
(0.026)\end{array}$ & $\begin{array}{r}\mathbf{0 . 6 1 5} \\
(0.027)\end{array}$ & 0.542 & $\begin{array}{c}0.508 \\
(0.023)\end{array}$ & $\begin{array}{c}\mathbf{0 . 5 7 1} \\
(0.025)\end{array}$ & $\begin{array}{r}\mathbf{0 . 5 9 0} \\
(0.025)\end{array}$ & $\begin{array}{c}\mathbf{0 . 5 9 1} \\
(0.026)\end{array}$ \\
\hline$N i k$ & 0.671 & $\begin{array}{c}0.522 \\
(0.025)\end{array}$ & $\begin{array}{c}0.605 \\
(0.026)\end{array}$ & $\begin{array}{c}\mathbf{0 . 6 2 7} \\
(0.027)\end{array}$ & $\begin{array}{c}\mathbf{0 . 6 2 6} \\
(0.027)\end{array}$ & 0.650 & $\begin{array}{c}0.514 \\
(0.024)\end{array}$ & $\begin{array}{c}0.586 \\
(0.026)\end{array}$ & $\begin{array}{r}\mathbf{0 . 6 0 6} \\
(0.026)\end{array}$ & $\begin{array}{r}\mathbf{0 . 6 0 5} \\
(0.026)\end{array}$ & 0.628 & $\begin{array}{c}0.509 \\
(0.024)\end{array}$ & $\begin{array}{c}0.566 \\
(0.025)\end{array}$ & $\begin{array}{c}\mathbf{0 . 5 8 4} \\
(0.024)\end{array}$ & $\begin{array}{r}\mathbf{0 . 5 8 3} \\
(0.025)\end{array}$ \\
\hline$U K$ & 0.662 & $\begin{array}{c}0.515 \\
(0.025)\end{array}$ & $\begin{array}{c}0.610 \\
(0.028)\end{array}$ & $\begin{array}{c}\mathbf{0 . 6 3 4} \\
(0.029)\end{array}$ & $\begin{array}{r}\mathbf{0 . 6 3 5} \\
(0.032)\end{array}$ & 0.641 & $\begin{array}{c}0.508 \\
(0.024)\end{array}$ & $\begin{array}{c}0.590 \\
(0.027)\end{array}$ & $\begin{array}{r}\mathbf{0 . 6 1 2} \\
(0.028)\end{array}$ & $\begin{array}{r}\mathbf{0 . 6 1 3} \\
(0.030)\end{array}$ & 0.617 & $\begin{array}{c}0.503 \\
(0.024)\end{array}$ & $\begin{array}{c}0.569 \\
(0.026)\end{array}$ & $\begin{array}{r}\mathbf{0 . 5 8 9} \\
(0.026)\end{array}$ & $\begin{array}{r}\mathbf{0 . 5 8 9} \\
(0.028)\end{array}$ \\
\hline$A U$ & 0.679 & $\begin{array}{c}0.520 \\
(0.025)\end{array}$ & $\begin{array}{c}0.612 \\
(0.027)\end{array}$ & $\begin{array}{c}\mathbf{0 . 6 3 4} \\
(0.029)\end{array}$ & $\begin{array}{l}\mathbf{0 . 6 3 5} \\
(0.029)\end{array}$ & 0.657 & $\begin{array}{c}0.512 \\
(0.024)\end{array}$ & $\begin{array}{c}0.592 \\
(0.026)\end{array}$ & $\begin{array}{l}\mathbf{0 . 6 1 2} \\
(0.027)\end{array}$ & $\begin{array}{l}\mathbf{0 . 6 1 3} \\
(0.027)\end{array}$ & 0.631 & $\begin{array}{c}0.507 \\
(0.023)\end{array}$ & $\begin{array}{c}0.571 \\
(0.025)\end{array}$ & $\begin{array}{l}\mathbf{0 . 5 8 8} \\
(0.026)\end{array}$ & $\begin{array}{c}\mathbf{0 . 5 8 9} \\
(0.026)\end{array}$ \\
\hline$T B 1$ & 0.672 & $\begin{array}{c}0.522 \\
(0.024)\end{array}$ & $\begin{array}{c}0.603 \\
(0.027)\end{array}$ & $\begin{array}{l}\mathbf{0 . 6 1 9} \\
(0.028)\end{array}$ & $\begin{array}{l}\mathbf{0 . 6 2 1} \\
(0.027)\end{array}$ & 0.642 & $\begin{array}{c}0.514 \\
(0.024)\end{array}$ & $\begin{array}{c}0.583 \\
(0.026)\end{array}$ & $\begin{array}{l}\mathbf{0 . 5 9 7} \\
(0.027)\end{array}$ & $\begin{array}{l}\mathbf{0 . 5 9 8} \\
(0.026)\end{array}$ & 0.610 & $\begin{array}{c}0.509 \\
(0.023)\end{array}$ & $\begin{array}{c}0.563 \\
(0.025)\end{array}$ & $\begin{array}{l}\mathbf{0 . 5 7 5} \\
(0.026)\end{array}$ & $\begin{array}{c}\mathbf{0 . 5 7 6} \\
(0.024)\end{array}$ \\
\hline$T B 2$ & 0.661 & $\begin{array}{c}0.520 \\
(0.024)\end{array}$ & $\begin{array}{c}0.597 \\
(0.027)\end{array}$ & $\begin{array}{c}\mathbf{0 . 6 1 1} \\
(0.027)\end{array}$ & $\begin{array}{r}\mathbf{0 . 6 1 2} \\
(0.027)\end{array}$ & 0.633 & $\begin{array}{c}0.514 \\
(0.024)\end{array}$ & $\begin{array}{c}0.578 \\
(0.026)\end{array}$ & $\begin{array}{r}\mathbf{0 . 5 9 1} \\
(0.026)\end{array}$ & $\begin{array}{r}\mathbf{0 . 5 9 2} \\
(0.026)\end{array}$ & 0.604 & $\begin{array}{c}0.509 \\
(0.023)\end{array}$ & $\begin{array}{c}\mathbf{0 . 5 5 9} \\
(0.025)\end{array}$ & $\begin{array}{r}\mathbf{0 . 5 7 1} \\
(0.025)\end{array}$ & $\begin{array}{c}\mathbf{0 . 5 7 1} \\
(0.024)\end{array}$ \\
\hline
\end{tabular}

Note: Emp stands for the empirical value of Lo's Hurst exponent, $k=5, k=10, k=15$ and $k=20$ refer to the mean and standard deviation of Lo's Hurst exponent based on the corresponding 1000 simulated time series with different $k$. Boldface numbers are those cases in which empirical $H$ s fall into the corresponding 2.5 to 97.5 percent quantiles of the 1000 simulation-based values of $H$. 